\title{
Measuring the Impact of Pretrial Diversion from the Criminal Justice System*
}

\author{
Franklin E. Zimring†
}

In 1967 the Vera Institute of Justice established the Manhattan Court Employment Project to divert criminal defendants, after their arraignment on felony or misdemeanor charges, into a program of group therapy and employment counseling. If a defendant succeeds in the program and obtains a job, his pending criminal charges are dismissed. The goals of this innovative program are eloquently stated in the Vera Institute's ten-year report:

The Manhattan Court Employment Project aims to stop the development of criminal careers by entering the court process after an individual has been arrested but before he has been tried, and giving him the kind of counseling and opportunity for starting on a legitimate career that he needs and otherwise is not able to obtain. The defendant is offered the possibility that the charges against him will be dismissed, provided he is cooperative and responds to counseling and job placement within a 90-day period granted by the court.

It is, in other words, an attempt to convert his-arrest from a losing to a winning experience-to build a bridge for the accused between the fractured world of the street and the orderly world of lawfulness and responsibility. The defendant wins because he gets a job he likes and the charges against him are dismissed ... and society wins also because an individual who may be develop-

- The data on New York City's Court Employment Project reported in these pages have been excerpted from a report I submitted to the N.Y.C. Human Resources Administration in November 1973. That research was supported by the Human Resources Administration and the Court Employment Project. Paul Herzick, Director of Research of the Court Employment Project, supervised the collection of the data used in this paper, and Ennis Olgiati, Director of the Court Employment Project, provided administrative and moral support to the enterprise. The views expressed in this paper are mine and are not necessarily shared by the Human Resources Administration or the Court Employment Project, although I hope they are. My critical focus on a Vera Institute of Justice project continues a long academic tradition of kicking only one's friends. Since its inception the Institute has been one of the most powerful change agents in the criminal justice system, and, at present, the Institute research staff is one of the finest in the United States.

$\dagger$ Professor of Law and Co-Director of the Center for Studies in Criminal Justice, University of Chicago; student of Hans Zeisel. 
ing a criminal life style has been converted into a working employee and taxpayer. Meanwhile, the criminal justice system has been relieved of the need to maintain him in jail or prison, perhaps regularly throughout his life. ${ }^{1}$

Measured by its community acceptance and the extent of its emulation in other cities, the Project is one of the most spectacular successes in the history of criminal justice reform. The Court Employment Project currently is a New York City corporation with a $\$ 3,000,000$ budget and 2,500 cases a year, which means that this program diverts more criminal defendants than many cities arrest; ${ }^{2}$ look-alike projects have been established all over the United States. ${ }^{3}$ In October, 1973, the United States Senate unanimously passed a bill providing for pretrial diversion and services in the federal system, modeled largely on the Court Employment Project; ${ }^{4}$ a similar bill is now pending in the House. 5

Two common research strategies, random assignment and matching exercises, are available to test whether early diversion programs have an impact on their participants. The most reliable method of assessing program impact is a random assigument experiment, in which people eligible for diversion are divided by lot into a test group that receives services in the program and a control group that returns to the criminal justice system for normal processing. ${ }^{6}$ If the project has more impact than the regnlar criminal justice system processes on factors such

I Vera Institute of Justice, Programs in Griminal Justice Reporm, Ten-Year Report 1961-71, at 80 (1972). The Manhattan (now New York) Court Employment Project was one of two pilot projects funded initially by the United States Department of Labor in 1967. Since then, the Department of Labor has funded nine other "employment diversion" projects in other cities. For an outline of the range of current diversion strategies, see Vorenberg \& Vorenberg, Early Diversion from the Criminal Justice System: Practice in Search of a Theory, in PrISONERs IN AMERTCa 151 (L. Ohlin ed. 1973).

2 See Court Employment Project, Report, Fiscal Year 1972-73.

3 It has been estimated that there are pretrial diversion projects operating in at least thirty jurisdictions. Vera Institute of Justice, Concept Paper: Proposal for the Evaluation of the New York Court Employment Project, Jan. 31, 1974 (unpublished manuscript on file at The University of Chicago Law Review). Estimates of the number of projects in existence may be expected to vary widely, because there is little agreement about what constitutes "diversion" or when a policy becomes a project. In New York City, the diversion capital of the United States, our partial count found thirty-nine special project programs offering either diversion or similar services to adults or juveniles, with nineteen of these programs offering pretrial services.

4 S. 798, 93d Cong., lst Sess. (passed Oct. 4, 1973).

5 H.R. 9007, 93d Cong., 1st Sess. (1973).

6 See D. Glaser, Routinizing Evaluation: Getting Fefeddack on Effectiveness of Crime and Delinguency Programs 55-83 (1973). 
as employment or tendency to be rearrested, this impact should appear as a difference in employment or subsequent arrests between the test and control groups.

Although controlled experimentation is more effective, matching exercises are by far the most popular device for assessing the impact of innovative treatment programs in the criminal justice system. ${ }^{7}$ With a matching strategy, data is collected on the characteristics of persons exposed to a new treatment; the researcher then constructs a group of untreated individuals whose characteristics appear to match those of persons in the treatment group. The performances of the treatment and matched nontreatment groups are compared, and any differences are attributed to the impact of the treatment. The matching strategy thus attempts to duplicate the similarity of groups created by random assignment by finding similar persons in similar positions. Unlike random assignment, matching exercises can be constructed from historical records after a treatment group has been selected and processed. Programs that lacked an initial research design can therefore use this approach to acquire some data about their effectiveness. Such after-thefact matching is quicker, cheaper, and vastly more dangerous than controlled experimentation. ${ }^{8}$

The initial evaluation of the Manhattan Court Employment Project was an after-the-fact matching exercise. ${ }^{9}$ This paper is an effort to describe the effects of that strategy on the quality of the research, on our present knowledge of the impact of diversion programs, and on the impressions held by the Project's staff and the general public regarding the Project's goals. After describing the initial research procedures and results, I will describe subsequent efforts to evaluate the Project's impact. If read in the spirit in which it is written, this paper is a plea for experimentation in law reform, rather than the nitpicking of a particular project or set of research procedures.

7 An American Bar Association study group evaluated eight attempts to study the impact of pretrial diversion on subsequent criminality by participants. One study was a simple before-and-after comparison of participant rearrests. Two studies, in Dade County and Des Moines, were initially designed as random assignment experiments with thirtyfive subject control groups. Five of the eight studies were after-the-fact matches of the type described in the text. See Miller, Evaluation of Research on Pretrial Diversion, Jan. 1974 (unpublished manuscript, National Pretrial Intervention Service Center, Washington, D.C.).

8 See D. GLASER, supra note 6, at 55-83.

9 See Manhattan Court Employment Project of the Vera Institute of Justice, Final Report November 1967-December 31, 1970, at 44 (1972) [hereinafter cited as CEP Final Report]. 


\section{The Manhattan Court Employment Project Evaluation-A First Look}

To test the impact of the Manhattan Court Employment Project (CEP) on recidivism, the Project research staff compared the rate of rearrests over a one-year period for three sample groups:

(1) 152 subjects who entered the Project during the first two years of Project operations and successfully completed treatment ("Project successes");

(2) 62 subjects who entered the Project during the first two years but failed to complete treatment ("Project failures"); and

(3) a control group of 91 criminal defendants arraigned in 1967, before the Project started, whose court records indicated that they would have been eligible for the Project ("Project controls").

Table 1 reports the percentage of rearrests in each group during the first year after leaving CEP (groups 1 and 2) or arraignment (group 3). ${ }^{10}$

TABLE 1

Percentage of Persons Rearrested Twelve

Months AFTER LEAving CEP OR ARRAIGNMENT

\begin{tabular}{ccc}
\hline Project Successes & Project Failures & Controls \\
16 & 31 & 32 \\
$(23 / 152)$ & $(19 / 62)$ & $(29 / 91)$ \\
\hline
\end{tabular}

SoURCE: CEP Final Report

Based on these data the report concluded: "Recidivism was substantially reduced for the dismissed participant group [successes] in comparison to the terminated [failures] and control groups."11

Presenting these data and a matching study from the CEP counterpart in Washington, D.C. (Operation Crossroads), the Senate Subcommittee on National Penitentiaries concluded that " $t$ the real benefit of pretrial diversion is the final result: The individual who has completed a program of pretrial diversion is much less likely to commit another crime than the individual who goes through the criminal justice system in the normal way.... In these ... projects, the likelihood of future recidivism was substantially reduced ...."12 Analyzing the differences noted in Table 1, the Subcommittee further argued:

It is important to note that charges against some of those selected for the comparison groups were dismissed for other reasons, which

10 Id. at $44-45$.

11 Id. at 50.

12 S. REP. No. 93-417, 93d Cong., 1st Sess. 7 (1973). 
clearly shows that the effectiveness of pretrial diversion lies not in the fact of dismissal, but in the intensive community-based program in which the individual participates. ${ }^{13}$

Unfortunately, a closer analysis of Table 1 casts some doubt on what the study "clearly shows." That the Project had a positive impact on rearrests cannot be demonstrated by a simple comparison of the record of Project successes with that of the matched control group. The subjects who succeed in treatment are a biased sample of all people who entered the Project; their success in treatment indicates that this group was, from the start, "most likely to succeed." Assuming for the moment that the control group is a perfect duplicate of people who enter the Project, the correct comparison is between rearrests among all Project participants and rearrests in the control group. The data in Table 1 require some tidying up before this comparison can be made. Although the data in Table 1 indicate a ratio of successes to failures of approximately three to one, in fact 45 percent of the participants succeeded in the Project during the period covered by the study.14 Table 2 uses this true figure to adjust the Table 1 data and arrive at an estimate of the proper comparison between the treatment and matched control groups.

TABLE 2

Estimated Pergentage of Rearrests for CEP

Participants and Matched Controls

\begin{tabular}{lrc}
\hline & Participants & Controls \\
Successes & $16 \% \times .45=7 \%$ & - \\
Failures & $31 \% \times .55=17 \%$ & - \\
\cline { 2 - 3 } Total & $24 \%$ & $-32 \%$ \\
\hline
\end{tabular}

Although this comparison is less dramatic than that between successes and controls, it still lends some support to the hypothesis that the Project is reducing the likelihood of rearrests of its participants. One problem with drawing that inference from Table 2-and the basic problem for all "matched group" studies-is the possibility that the groups being compared are essentially dissimilar.

I investigated, with the aid of the CEP research staff, whether the test and control groups in the initial study were comparable groups. The control group was composed of "arrestees who, on the basis of their court papers, might have been eligible to participate in the

13 Id.

14 According to Project records, 416 of the 929 Project entrants during 1968 and 1969 eventually succeeded in treatment. 
Project,"15 and our initial task was to determine whether the actual project participants were selected in the same way as the controls.

We began by putting the Project in its context, the New York City criminal justice system. In 1971 approximately 75,000 people were arraigned for felonies and misdemeanors in Manhattan; 1.2 percent (871) participated in GEP. The Project selects its participants from individuals who are arraigned on weekdays. Screeners review the papers of all defendants and elect either to "write up" a defendant, if the Project's eligibility criteria are met, ${ }^{16}$ or to reject him as a Project prospect. Screeners then interview defendants who have been written up and obtain an Assistant District Attorney's approval of the defendant's participation. An Assistant District Attorney then requests the presiding judge to adjourn the case so that the defendant may participate.

To study the screening process ${ }^{17}$ we obtained a sample 205 consecutive docket numbers indicating weekday arraignments during October, 1971. As indicated in Figure 1, one out of five criminal defendants

FIGURE 1

Results of Screening Process for 205 Consecutive Weekday Arraignments in Manhattan DuRing October, 1971

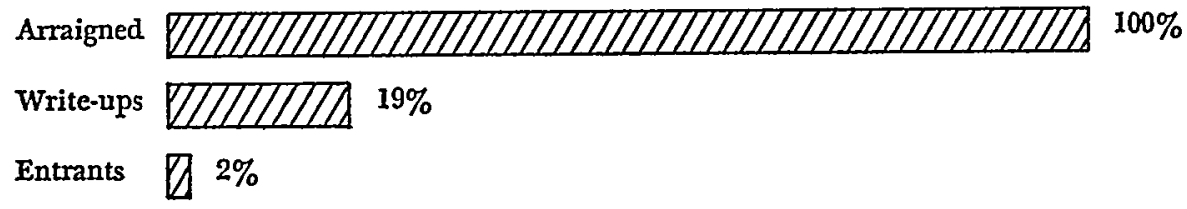
SOURCES: CEP and Court.Recordds.

were written up, but thirty-five of the thirty-nine who were written up did not enter the Project.

Since the matched controls in Tables 1 and 2 are defendants who

15 CEP Final Report, supra note 9, at 45.

10 The Project's current announced eligibility criteria are:

1) Sex, Age: males and females between the ages of 16 and 60;

2) Residence: New York City residents (except certain areas of Queens and all of Staten Island);

3) Employment Status: unemployed or, if employed, not earning more than \$140 per week; full time students are eligible;

4) Charge: no charge for which the arrestee would actually serve a sentence following a conviction, and no addicts or alcohohics;

5) Pending Cases: not more than one pending charge; and

6) Prior Record: not liave served more than one year in a penal institution.

See CEP, The Court Employment Project (1973) (Pamphlet).

17 CEP screening procedures were tightened in 1969 but have apparently remained fairly constant since. See CEP Final Report, supra note 9, at 46-48. 
would have passed only the "write-up" screening, the matching exercise is actually a comparison of a control group that has been screened once with a test group that has been screened twice; that is, Table 1 compares the later records of a sample of the 19 percent who would be eligible for write-ups with the later records of the 2 percent who actually entered CEP. To discover why so few of the people who pass the Project's first screening became participants, we analyzed 201 consecutive write-ups from 1972, since the data from the 1971 sample were unavailable, and Table 3 shows the reasons for exclusion, as noted by the screeners.

TABLE 3

REASONS FOR EXCLUSION FROM GEP AMONG 201 CONSECUTIVE WRITE-UPS IN 1972

\begin{tabular}{lr}
\hline Drug or alcohol involvement & $20 \%$ \\
Defendant pleaded guilty & $15 \%$ \\
Defendant rejected program & $14 \%$ \\
Bench warrant outstanding & $10 \%$ \\
Defendant's charge dismissed & $8 \%$ \\
Another program & $6 \%$ \\
Other & $15 \%$ \\
Total not entering & $86 \%$ \\
Eutered & $14 \%$ \\
\hline
\end{tabular}

SOURCE: CEP Records

Table 3 shows that no matched group selected solely from records can be considered comparable to a sample of Project participants. The matched control group should contain more persons with alcohol or drug problems, because, even after a record inspection to delete drug cases, some write-ups are eliminated at the interview screening because of drug or alcohol problems; indeed, the number of write-ups eliminated because of such problems (20 percent) is greater than the - number that ultimately enter the Project (14 percent). ${ }^{18}$ The participant

18 The later arrest patterns of the participant and control groups give some indication of the importance of screening out drug-dependent offenders and show that the Project screened at a progressively stricter level. Among subjects admitted to the Project in the first fourteen months of operation, the rate of later drug arrests was actually higher than that of the controls- 19.4 percent to 8.8 percent. The percentage of this treatment group that was rearrested within a year was the same as the control group, 32 percent. Those cases admitted during the next year had a rate of later drug arrests that was one-third of the control group (3 percent compared to 9 percent), and it is this group that produces the favorable total recidivism comparison (18 perceut versus 32 percent). The CEP report attributes the improvement to better screening, but does not acknowledge the possibility 
group was probably more amenable to treatment than the matched group, because a substantial number of eligible persons declined to enter the Project; the rate of rejection of the Project is as large as the rate of acceptance. ${ }^{19}$

Two intermediate conclusions can be drawn at this point from our adventures with the CEP matching exercise. First, since the comparison used dissimilar matched groups, the rearrest figures in Table 2 are not good evidence that the Project has an impact on its subjects. Second, in evaluating the impact of any program that recruits volunteers, volunteer subjects cannot be matched with nonvolunteer controls without creating grave doubts about the assumption that the groups would have had similar later careers but for program intervention. This second point is of general importance, since most correctional intervention experiments require voluntary subject cooperation and most evaluation efforts of these projects involve matching. A third point is almost too basic for reiteration: matching exercises for projects that screen for participants must use the same type of screening to find appropriate comparison groups. The question now is whether there is any way that these basic lessons can be applied to provide a better matching exercise than that reported in Table 2.

\section{Silk Purses out of Sow's Ears?- ANother Matched Group Study}

There is one after-the-fact match that is less objectionable than the exercise just reviewed. Truly comparable groups can be constructed from those persons whose paper records appeared to make them eligible for the Project (some of whom actually entered the Project) and those persons who were not screened for the Project but who would have passed the paper record screening. Any differences between the later records of Project participants and those who would have been treated, if they had been screened, would appear in the form of smaller differences between the two larger eligible groups. Such a comparison is handicapped by the fact that only 14 percent of this test group is actu-

that this improved screening, rather than Project impact, produced the favorable recidivism figures. For data on rearrests, see CEP Final Report, supra note 9, at 46-48.

10 See Table 3 supra. Other diversion programs, such as Project Crossroads (Washington, D.C.) and the Dade County, Florida, project recruit participants from more than one pool, which would complicate the task of determining how many of those offered admission into the program agree to enter. Project Midway (Nassau County, New York) reports that about three-fourths of those eligible elect to enter the project; only accused felons are eligible for this program. See Miller, supra note 7, at 52. 
ally exposed to treatment; a reduction of 30 percent in participant rearrests would appear as a 4 percent difference in rearrests between the two larger groups. It is thus improbable, even with the best possible matched group, that a matching comparison would yield anything more than the most tentative indications of Project impact.

A second problem is finding a group of New York City criminal defendants not subject to CEP screening from which a group of "writeup" controls could be drawn. Since CEP does not screen on weekends, one source of comparison write-ups is a representative sample of defendants arraigned on weekends. A second possibility is a group of defendants processed before CEP started screening. Rearrests are used as a measure of criminality, however, and there are dangers in comparing rearrest rates of one group at one time with another group at another time. The rate of arrests per 100 crimes in New York City may have changed; a lower probability of apprehension would appear as lower reported criminality among the group benefiting from less effcient law enforcement. ${ }^{20}$

We therefore decided to obtain a sample of defendants who had passed CEP's first screening and a comparison group of defendants who were arraigned on weekends during the same months. Later arrest records were obtained for 439 weekend defendants who met CEP criteria and 353 weekday defendants who had passed the Project's first screening. ${ }^{21}$ The members of the weekend group were different in several possibly significant respects, including the fact that they were slightly older than the weekday write-ups, ${ }^{22}$ but they had the same distribution

20 This is one of the many problems with Table 1 , supra.

21 Only 49 of the 353 (14 percent) entered the Project.

22 The age breakdown by percent for the two write-up groups is:

$\begin{array}{lcc}\text { Age } & \text { Weekday } & \text { Weekend } \\ 16-17 & 20 & 14 \\ 18-20 & 23 & 24 \\ 21-29 & 40 & 39 \\ 30 \text { and over } & 17 & 23 \\ & 100 \%(353) & \frac{100 \%}{1439)}\end{array}$

There were also some percentage differences in charges filed against the members of the two groups:

Charge

Assault and Weapons

Burglary

Larceny and Theft

Drugs

Other
Weekday

15

16

42

5

22

$\overline{100 \%}(353)$
Weekend

25

14

30

9

22

$\overline{100 \%}(439)$ 
of prior arrests. ${ }^{23}$ Table 4 compares the percentage of people rearrested within one year after normal treatment time for the weekday group (which has some members who were treated), the weekend group (which does not), and the group used as the original control in the Project Report.

TABLE 4

Percentage of Defendants Rearrested within One Year After Normat Treatment Period (By Age)

\begin{tabular}{lccc}
\hline Age & Weekday Write-ups & Weekend Write-ups & Original Controls \\
\hline $16-17$ & 47 & 38 & \\
$18-20$ & 41 & 40 & \\
$21-29$ & 31 & 25 & \\
30 and over & 15 & 17 & $32 \%$ \\
All ages & $\frac{15}{29 \%}$ & $44 \%$ & \\
\hline
\end{tabular}

- Not available

SOURCEs: N.Y. Police Dept. Bureau of Criminal Information (weekday and weekend write-ups); CEP Final Report, supra note 9.

The higher age-specific rate of recidivism in the group including participants casts some doubt on the claim that the project has reduced participant rearrests.

A further step can be taken to test whether the Project reduces recidivism among its participants. The percentage of actual entrants is greater in the younger age groups, as shown by Figure 2 .

FIGURE 2

Percentage of Write-ups Entering CeP (By Age)

\begin{tabular}{|c|c|c|}
\hline & Entered & Did Not Enter \\
\hline I6-17 & $D I I / 22 \%] 11 \lambda$ & $78 \%$ \\
\hline $18-20$ & {$[717 \% / 7 \lambda$} & $83 \%$ \\
\hline $21-29$ & $110 \% / \lambda$ & $90 \%$ \\
\hline 30 and over & $9 \%$ & $91 \%$ \\
\hline
\end{tabular}

SOURCES: CEP and Court Records.

If the Project had an impact on rearrests, the weekday write-up age groups with a higher percentage of participants (the younger groups) should fare relatively better than the age groups with a lower percent-

23 The percentage breakdown of the two groups by prior arrests:

$\begin{array}{lcc}\text { Arrests } & \text { Weekday } & \text { Weekend } \\ 2 \text { or more } & 22 & 23 \\ 1 & 18 & 16 \\ \text { None } & 60 & \frac{61}{100 \%}(439)\end{array}$


age of participants when each is compared with its weekend age group control. The two groups with the highest percentage of participants, however, do not compare more favorably with their group controls, as shown by Table 4. This absence of any favorable indication remains when the comparison is of total number of arrests per 100 subjects, ${ }^{24}$ rather than subjects arrested, and when different charge categories are separated out. ${ }^{25}$

24 Age-specific felony and drug offense rearrests per 100 man-years (100 subjects for one year after normal treatment period) for the weekday and weekend groups:

$\begin{array}{lcc}\text { Age } & \text { Weekday } & \text { Weekend } \\ 16-17 & 49 & 38 \\ 18-20 & 41 & 49 \\ 21-29 & \mathbf{3 3} & 27 \\ 30 \text { and over } & \overline{9} & \overline{14} \\ \text { All ages } & \overline{34} & \overline{31}\end{array}$

The group with the highest concentration of program participants (16-17) has the poorest record relative to its controls, and there is no discernible overall relationship between extent of program participation and performance relative to the weekend group.

25 The last step in this series of comparisons involves rates per 100 man-years of felony and drug arrests for the test and control groups. In this comparison the group is divided into five categories of present charges and four age groups.

Felony and Drug ARrests per 100 Man.Years, WeEkday and Werkend WrTte-ups, MANHATTAN SAMPLE 1971
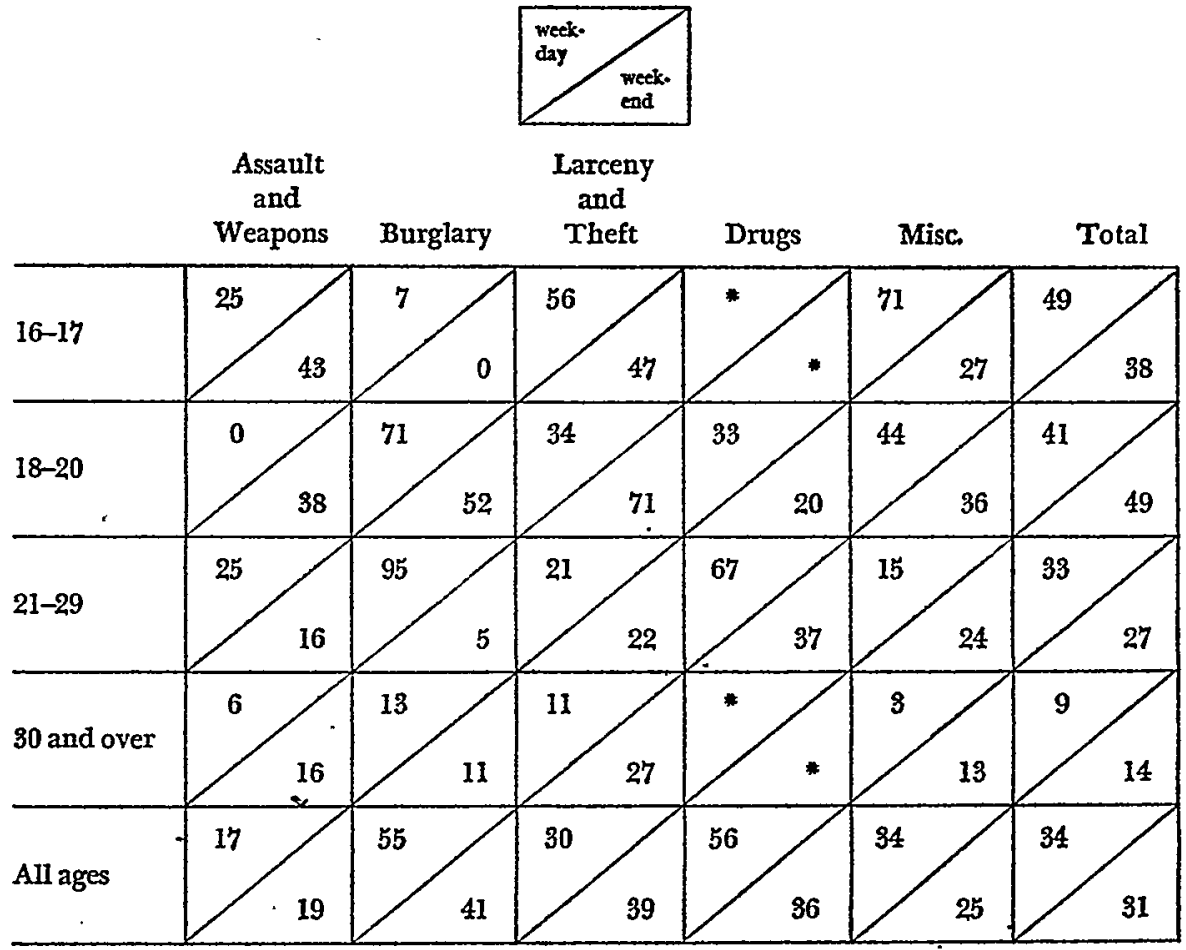

* Deleted because test or control group contained fewer than four defendants. 
These negative indications do not rule out the possibility that the Project reduces rearrests. Each comparison made in Table 4 involves a test group that is composed of at least 78 percent untreated subjects, which is hardly an ideal condition. And if, for example, younger weekend defendants are less similar to their weekday matches than older defendants are to their matches, the lack of improvement as concentration increases could conceal a positive Project impact.

We do not know whether the similarity of rearrest rates indicates that the Project has no more impact than normal criminal justice treatment or whether it is a product of the weakness of the research design. What is clear, however, is that the only way to find out is to initiate, after seven years of Project operation, random assignment experiments.

\section{BARRIERS TO EXPERIMENTATION}

The Project directors have stated two reasons for the failure to institute a random assignment experiment at the outset of the Project's operation. First, "the experimental nature of the Project demanded initial emphasis on effective day-to-day operations." 26 This reasonthe press of circumstances-is a general plea in mitigation and need not detain us long. An unfriendly critic might even paraphrase: "the program was too experimental to be an experiment." The second reason was a belief that "denying participation for the purposes of research violated the humanitarian tenets of the Project and the sensitivities of the staff."27 This problem-the ethics of denying treatment to controls for research purposes-is more substantial and has been the subject of lively debate in recent literature. ${ }^{28}$ We can sharpen our understanding of the issues, however, if we define the types of experiments that might be used to evaluate diversion projects before confronting the issue of their humanitarian implications.

The present structure of early diversion raises two important questions: what is the impact of diverting persons from prosecution for

The rate of felony and drug arrests during the period from four to fifteen months after arraignment was 34 per 100 man-years for the test group and 31 per 100 man-years for the control group. When the comparison is controlled for age and charge differences, the "test" group wins eight comparisons and the "control" group wins ten. The correlation between Project concentration (which varied in the eighteen cells from 0 to 40 percent) and relative test group comparison is .05 , again suggesting that the percentage of a test cell that enters the Project is not related to the relative performance of the test group when compared to the control group.

26 CEP Final Report, supra note 9 , at 44.

27 Id.

28 See, e.g., Morris, Impediments to Penal Reform, 33 U. CuI. L. Rev. 629, 649-53 (1966); Zeisel, Reducing the Hazards of Human Experiments Through Modifications in Research Design, 169 ANnals of N.Y. ACAD. OF Scr. 475 (1970). 
crime, as compared to continuing normal criminal justice processes, and what is the effect of the services provided by such projects on the lives of their participants? In examining the impact of treatment facilities, an important and expensive component of programs like CEP, it is not necessary to sacrifice any major humanitarian values. An experiment could randomly assign diverted defendants into two groups, one group would receive therapy and job counseling and the other would receive a postponement of charges that matures into a dismissal of pending charges if the defendant is not rearrested. If either group is disadvantaged here, it is probably the test group, because they are compelled to participate in a program that many criminal defendants find unappealing. ${ }^{29}$

On the other hand, to test whether the impact of treatment plus diversion is different from normal prosecution, it would be necessary to refuse diversion to a randomly selected group of defendants, either before they agree to enter the Project ${ }^{30}$ or after they have qualified as willing entrants. ${ }^{31}$ The Project would thus leave some defendants at the peril of criminal prosecution for "research purposes." Without ignoring the problematic quality of such a procedure, three points will put the issue in perspective. First, there is currently a group of defendants who are not eligible for project participation, but who are no less deserving of consideration than any possible control group, that is, defendants arraigned on weekends. Whether this exclusion is a matter of convenience or a conservation of scarce resources cannot be determined, but since the number of defendants diverted and treated would not be affected by an experiment, the problems of denying services to controls are no greater than denying eligibility on weekends, and the benefits of the policy of random assignment are much greater. ${ }^{32}$

Second, the defendants placed in the control group would not be subject to heavy criminal sanctions. Less than one-fifth of the defendants who would have passed the Project's write-up screening are detained before trial. ${ }^{33}$ Since the defendants who are offered treatment are

29 As Table 3 shows, 14 percent of the eligible defendants in the 1972 sample rejected Project participation.

30 One could randomly assign the defendants who pass the second screening (which would not include inquiry into willingness to participate) to test and control groups and then compare the records of all defendants offered admission with those who were not.

31 One can test both services and diversion by dividing eligibles into three groupsdiverted and treated, diverted and not treated, and people returned to the criminal justice system. A proposal for this experiment has been prepared by the Vera Institute. See Vera Institute of Justice, supra note 3.

32 See Zeisel, supra note 28.

33 In our study of weekday and weekend write-ups, 19 percent of the weekend group were detained before trial, while only 13 percent of the weekday write-ups were detained. 
a select "best-risk" sample of this group, their pretrial detention rate would probably be lower. In any event, vigorous release-on-recognizance work could minimize the number of controls detained before trial. Further, the punishments received by people eligible for diversion are far from awesome, as can be seen by examining, in Table 5 , the case outcomes of weekend defendants who would pass the Project's first screening.

TABLE 5

Percentage Distribution of Dispostrion at Sentencing

STAGE BY SERIOUSNESS OF OUTCOME FOR WEEkEND WRITE-UPS in 1971 ManhatTan Sampte

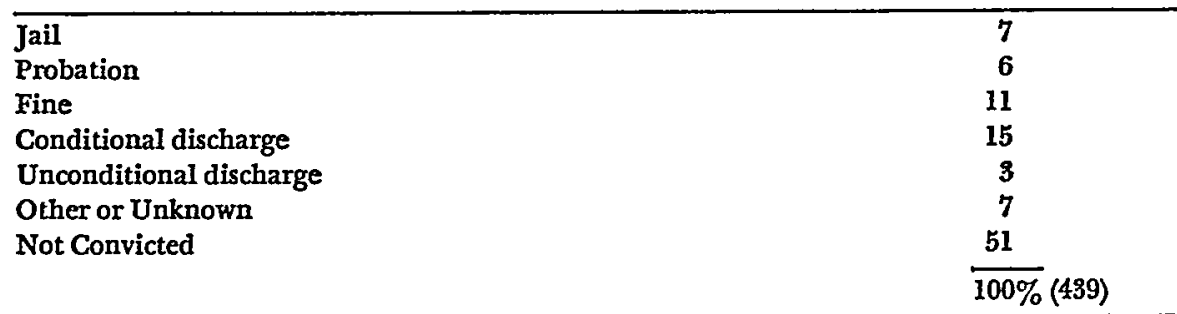

SOURCE: Court Records

About half of the eligible defendants in our weekend sample who remained in the criminal justice system were not convicted of any charge, and only 13 percent were sentenced to jail or probation. Again, the defendants who passed the second screening would, as a group, be expected to fare better. In fact, the Project accepts only defendants who would not serve a sentence if convicted, ${ }^{34}$ and no Project failures in the sample used for Table 4 were sentenced to jail when they returned to the system.

These data help explain the existence of the third reason why experimental control is not deeply objectionable for a CEP-style projectin Manhattan half of the defendants offered Project participation refuse. ${ }^{35}$ Withholding the offer might work some hardship on willing controls, but when the value of the Project is deemed so marginal by its potential clientele, the humanitarian objections to experimental controls are as close to de minimis as are likely to be found in criminal justice reforms. ${ }^{36}$ Moreover, it is worth noting that data about the operations of the criminal justice system are of value in determining the extent of possible ethical problems.

84 See note 16 supra.

85 See Table 3 supra.

30 An uneasy compromise with random assignment appears to have occurred in the Dade County and Des Moines projects. See note 19 supra. The principle was accepted, but the control groups selected were so small (thirty-four and thirty-five, respectively) that the chances of producing worthwhile knowledge were greatly diminished. 
This paper has now advanced two complementary arguments: we cannot obtain reliable data on the impact of early diversion programs without genuine experiments, and the ethical barriers to experimentation, at least in the New York context, are not as great as might have been supposed. One further topic is worthy of special mention: the consequences of matched group evaluations for the operation of earlydiversion programs. The most obvious result of nonexperimentation is the lack of information about the impact of diversion on its clients. In less obvious ways, however, the lack of real information and the fool's gold of encouraging matched group studies have affected the character of diversion programs.

Early diversion is best viewed as a multigoal process offering two scarce commodities-nonprosecution and expensive, ${ }^{37}$ albeit coerced, treatment services-to a small proportion of criminal defendants. The goals of such programs include building job skills, providing job placement, reducing recidivism, and ameliorating the harmful consequences of contact with the criminal justice system. Under these conditions, a number of trade offs are necessarily encountered in selecting the defendants eligble for such projects and in allocating project resources. For example, should the project divert the defendants who will represent the lowest risk to the community or the defendants who will benefit most from the treatment? If project treatment reduces criminality, these two groups will not contain the same type of defendant. The lowest risk to the community is created when the group least likely to be arrested in any event is returned to the streets. Treatment cannot greatly improve this group, if only because it does not have far to go. In contrast, effective treatment is most efficiently directed to the defendants who need such treatment most, because they exhibit a higher degree of danger, even though community treatment of this group presents greater danger of further crime. If scarce penicillin cures both pneumonia and colds, it is allocated first to the pneumonia cases.

Most early-diversion programs, however, have turned their attention to curing colds. The use of crude matching controls, or no controls at all, reduces the ability of diversion projects to show the effect of their programs, and puts pressure on them to "look good" in the only way they can-by reducing rearrests in the treated group to the bare minimum. Elaborate screening tends to produce "best risk" cases. Diversion

37 The present cost per case of the Court Employment Project is approximately $\$ 1000$, with the bulk of the money being spent for treatment facilities and staff. For specific data on costs and personnel, see CEP Final Report, supra note 9, at 50-54. 
projects across the country proclaim in-program rearrest rates as low as 2 percent. ${ }^{38}$ Studies of subjects one year after treatment report rearrest percentages that vary but cluster around 20 percent $^{38}$

In the same way that the absence of controlled comparison puts pressure on programs to select good risks, rigorous random assignment liberates treatment programs by providing a new basis of measuring treatment effects-the performance of controls. With random assignment, pressure to minimize the community risk generated by experimental treatment will still exist, but the most dramatic evidence of treatment impact will be produced by using higher-risk groups-cutting recidivism in half is more important if that reduction is from 60 percent to 30 percent than if it is from 20 percent to 10 percent. A low risk policy is not necessarily wrong. If the treatment has no appreciable impact, the low-risk approach is superior. It is only if the programs are as effective as these matching studies suggest that a low-risk selection policy is inappropriate.

A second trade off inherent in the nature of early diversion is between the number of cases that can be diverted and the quantity of service and supervision available for each subject. With scarce resources, much service can be provided to few defendants or less service to a greater number of defendants. To the extent that, in the words of the Senate Subcommittee, "the effectiveness of pretrial diversion lies ... in the intensive community-based program," 40 the best course is to concentrate services among a small group of recipients. To the extent that diversion rather than the services influences the later career of participants, a program that diverts more defendants or reduces program cost is more desirable. The matched group studies have tended to emphasize delivery of services to defendants and have created the "service" emphasis of the current federal proposals. It is not necessarily wrong to concentrate services on a relatively small group of recipients, as long as the treatment program reduces rearrests or has other worth-

38 Dade County Pretrial Intervention Project, Eighteen Month Report (1973). The same report shows a 0 percent rearrest rate for so-called Group III successes, which indicates either that the treatment is a superb success or that this group does not require intensive supervision and treatment. In a noncontrolled evaluation, the best apparent outcome will be achieved by treating a zero-risk group. Other in-treatment recidivism figures are: Crossroads (Washington, D.C.), 8.5 percent; Midway (Nassau County), 3 percent; and De Novo (Des Moines), 11.7 percent. See Miller, supra note 7, at 49, 51, 58, 54 .

39 Miller presents the following one-year-after data: Des Moines, 20 percent (felony convictions); Crossroads, 21 percent; Mental Health Diversion (Washington, D.C.), 12 percent. Miller, supra note 7 , at $49,51,53,54$. Two other projects-Nassau County and Dade County-report much lower figures, but the exposure time on which they are based is not known. See id. at 49,55 .

40 S. REP. No. 93-417, supra note 12. 
while impact on the lives of the treated group. But it is particularly ironic that the crude evaluation efforts create pressures towards using low-risk groups at the same time that they argue for high-intensity service programs to a small number of defendants. Either the wrong group is receiving the right services (if treatment reduces recidivism) or the right group is receiving the wrong treatment (if the major emphasis should be on diversion rather than services).

Other issues of resource allocation have been affected by the early efforts to evaluate diversion. Programs like CEP began with a heavy emphasis on recruiting unemployed individuals and finding them jobs. Recently, more participants have had jobs when they enter the Project, and more than half of the successful participants do not change from unemployed to employed during the course of treatment. This shift results in part from a response to a changing job market and in part from an effort to recruit low-risk defendants. In both instances the change represents a major shift in the focus of such programs.

Two further trends in early diversion programs are probably related to the euphoric initial evaluations. First, there is a temptation to stop experimenting with program structures or missions soon after their introduction into the criminal justice system. Once a program develops a format and demonstrates its effectiveness to its sponsors' satisfaction, the time for major innovation has passed. In this sense diversion projects may become the sacred calves of the criminal justice system. All in all, it is sad; we know so little, we do so badly, in this area of social control.

The second trend associated with early evaluation is, if anything, more destructive than the premature ossification of such programs: the first evaluations may have led proponents of diversion to misdefine the proper goals of such programs. For example, our reevaluation of CEP tended to show that when defendants are diverted from the ordinary processes of the criminal justice system, they do no worse than those who are fully processed through the police, courts, and correctional systems in New York City. This result could be regarded as a sufficient mandate for a program that seeks to inject humanity into a system that is not known for either excessive humaneness or demonstrated effectiveness. The early studies finding dramatic reductions in rearrests, however, may have led supporters of diversion programs to expect far too much from such reforms. At this writing, no correctional intervention strategy short of capital punishment has reduced subsequent recidivism by as much as one-half. The early matched group evaluations of diversion may force diversion proponents to demonstrate this type of impact or be considered failures. If, however, such programs can achieve a limited success in avoiding the stigma of criminal conviction and pro- 
viding offenders a second or third chance without disproportionate community risk, they will have achieved more good than harm. It would be sad indeed if early indications, based on defective analysis, were to lead diversion programs unnecessarily to claim benefits not essential to the case for their continuation.

\section{ConcLuston}

Diversion programs, if designed and executed humanely, are probably a healthy reform in the present state of American criminal justice. As a result of uninformed evaluation efforts, they are also oversold and widely misconceived.

The only cure for a poor evaluation is a good one-in this case, large-scale and careful random assignment experimentation, a procedure that may well be in process by the end of this year in New York. Yet there is a larger issue lurking in the story of the Court Employment Project. Program evaluation is presently a growth industry, but the quality controls on legal reform research are few. In the coming years the job of empirical research in law reform is not that of achieving lip service recognition but of demonstrating its value as a policy science. 